\title{
‡USES
}

science for a changing world

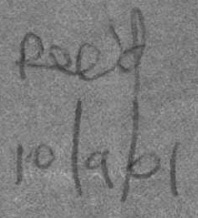

\section{Unconsolidated Aquifers in Tompkins County, New York}

Water-Resources Investigations Report 00-4211

Prepared in cooperation with the Tompkins County Planning Department

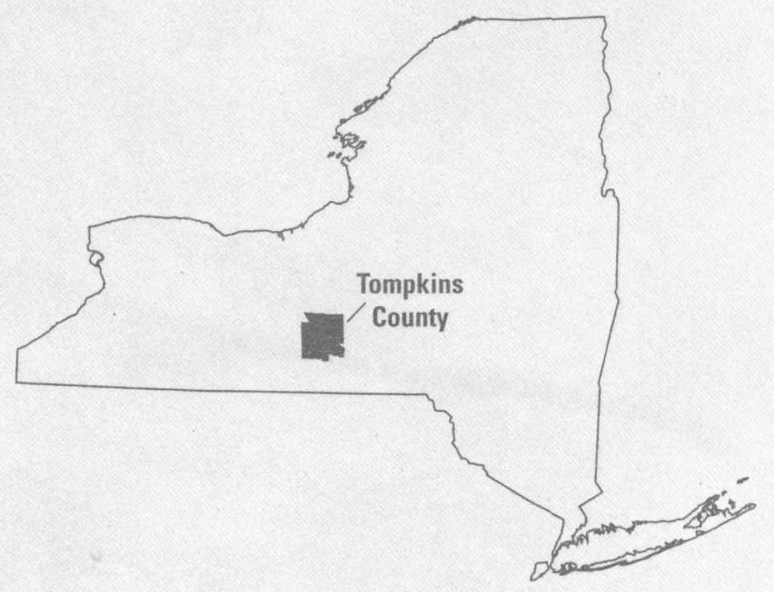

U.S. Department of the Interior

U.S. Geological Survey

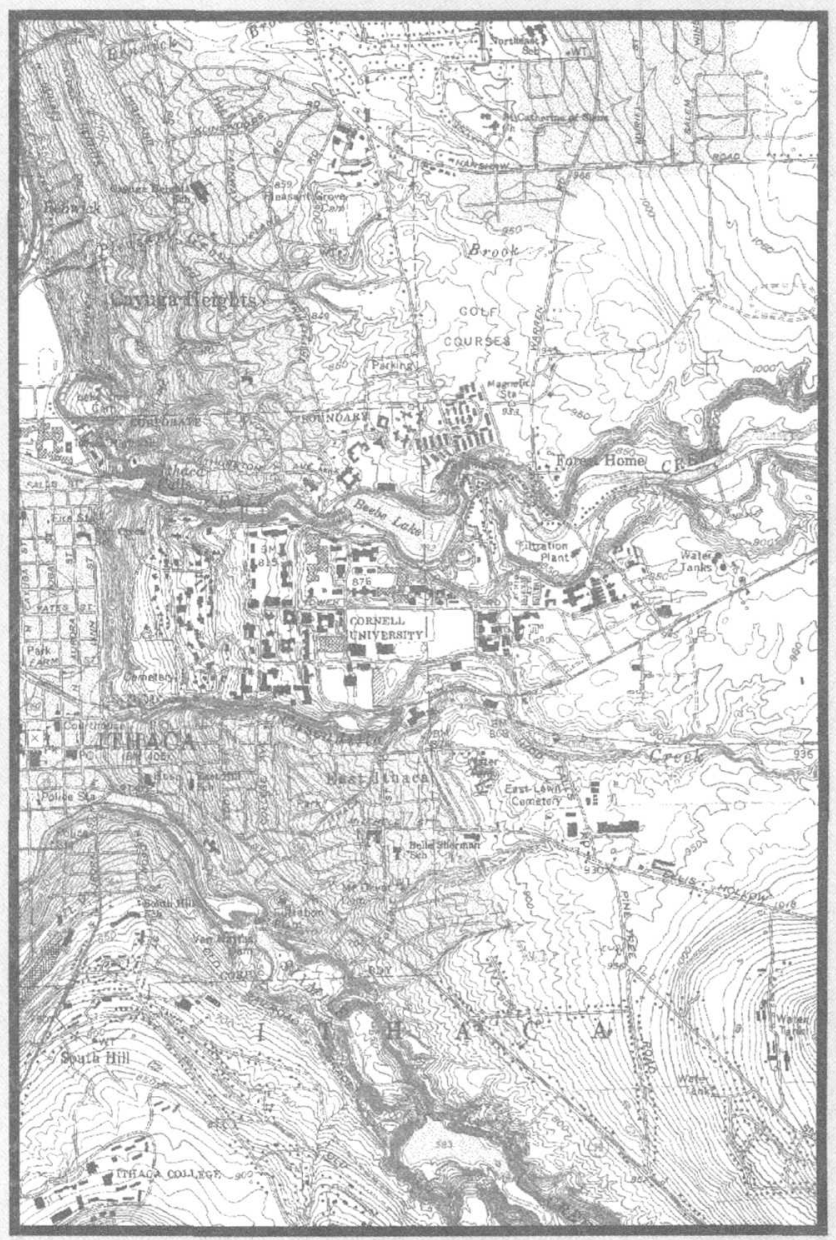


For Additional Information Contact:

Subdistrict Chief

U.S. Geological Survey

30 Brown Road

Ithaca, New York 14850
Copies of this report can be purchased from:

U.S. Geological Survey

Branch of Information Services

Box 25286

Denver, CO 80225 